\title{
3D Visualization of Railway Development Using GIS and BIM Techniques
}

\author{
Zhibo LIU, Feng HAN ${ }^{1}$, Guoqing NI, Tao LIANG, and Miaomiao QI \\ College of Civil Engineering, Lanzhou Jiaotong University, Lanzhou 730070, China
}

\begin{abstract}
Along with the proposal of the Belt and Road initiative, the Eurasian railway lines with China and Russia as the center are entering a new era of strategic coordination. Thus, carrying out digital location design with modern mapping information technology has become a necessary means for improving railway locating efficiency and quality. Employing the GIS-based large 3D strip terrain modeling approach and its application, the present study takes consideration in factors such as slope, relief, geological disasters, and locatinginfluencing surface features so as to construct the most economically efficient routes and form the optimal GIS-based plans and decisions. Specific railway lines undergo BIM locating design with an integrated use of Civil 3D and Infraworks360 software. Line modeling and earthwork calculation are conducted in the Civil 3D-based terrain curvature. Moreover, line model is imported into Infraworks360 to achieve a $3 \mathrm{D}$ roaming demonstration. A $3 \mathrm{D}$ visualized implementation of railway location design is made possible using GIS+BIM approach that improves locating efficiency and design quality.
\end{abstract}

Keywords. Digital railway locating, GIS, cost path, 3D modeling

\section{Introduction}

Railway locating is a complicated decision-making assignment that involves multiple objectives [1, 2], as it features wide range, high technical specifications and extensive issues. All the factors involved may affect the construction cost of railway locating plans, though in varying degrees. In order to meet the requirements concerning positive economic development and sustainable ecological environment, such railway locating principles as "economical, safe and environmental-friendly" should be followed. For instance, references $[3,4]$ explored the factors influencing railway locating design from environmental sustainability, integrated economic cost and engineering safety. In traditional locating work, designers' experience is more relied on to develop geological examination. Consequently, the resulting artificially designed locating plans are plagued by subjectivity in some sense as well as long design cycle. Accompanying the proposal of the Belt and Road strategy by our country, how to connect the Silk Road Economic Belt with Eurasian Economic Union has become the primary issue. It is increasingly difficult to carry out spatial line design with manual work alone against the complicated geographical conditions of all related countries. It is, thus, urgent to find an efficient locating approach to overcome those difficulties.

\footnotetext{
${ }^{1}$ Corresponding Author, Feng Han, Pucheng, Shanxi, PhD, professor. E-mail : 153025377@qq.com.
} 
As advanced digital information technology and modern surveying instruments continues to proceed, digital line examination and design has become a trend [5]. In the design of 3D route selection, GIS and BIM act as the main technical support, and their strong spatial analysis and information modeling capabilities make $3 \mathrm{D}$ visual route selection possible [6]. In the early stage of digital route selection, Professor Kong Jinling [7] in China first proposed the research concept of using GIS for road route selection. References [8-10] discussed the application analysis model of railway route selection design based on GIS, and put forward the comprehensive analysis and evaluation model of railway location plan. References [11] studied the factors affecting the route selection, and proposed that the railway route selection based on GIS could save a lot of time for line plane design. Although the GIS digital route selection technology is gradually improving, it still cannot get rid of the problems of 2D design line. It's non-intuitive and difficult to check the potential design problems, especially in the case of more complex modern railway. Therefore, the introduction of BIM technology has been largely successful in solving the problem. The combined use of GIS and BIM in the railway industry is also preliminarily discussed $[12,13]$. Reference [14] analyzed the improvement that BIM and GIS have made in the construction industry and the integrated application of the two at different levels, then pointed out that the combination of technology could improve and speed up the construction plan, and ensured the integrity and accuracy of the data. Reference [15] analyzed the actual application of BIM and GIS integration in recent years, summarized the advantages and disadvantages of existing research from four aspects, then proposed a more effective development method using data analysis and visual design, and clarified the development direction of GIS and BIM integration. Therefore, the integration use of BIM and GIS technology can better strengthen the construction of railway information $[16,17]$. The application of BIM Technology in railway construction is also regarded as one of the key tasks of railway technology innovation in China's 13th Five-year Plan. In this paper, a segment of the railway line from Shiquan to Gaoliang County was used as a test section. Based on GIS and BIM technology, various indicators that could affect the route selection were comprehensively considered to realize intelligent route selection. The 2D route was also constructed into a three-dimensional route model, and the design intention of the route plan was clarified through roaming display in order to improve the work efficiency of the industry.

Therefore, the study of GIS+BIM railway line 3D visualization route location method not only makes up for the lack of 2D drawings in 3D display, but also promotes the objective and scientific decision-making of railway location, which will have great significance for railway location design.

\section{The Construction of a Large Ribbon 3D Geographic Model}

\subsection{Modeling Method}

As a kind of systematic geographic information software, GIS uses 3D visualization technology to express geospatial information in $3 \mathrm{D}$ form, which is conducive to the comprehensive analysis of geographical model. In this paper, ArcMap was used to preprocess the data, and TIN was constructed to express the elevation analysis and various factors which affected railway location. After that, 3D geographical model was displayed in ArcScene. The modeling process is shown in Figure 1. 


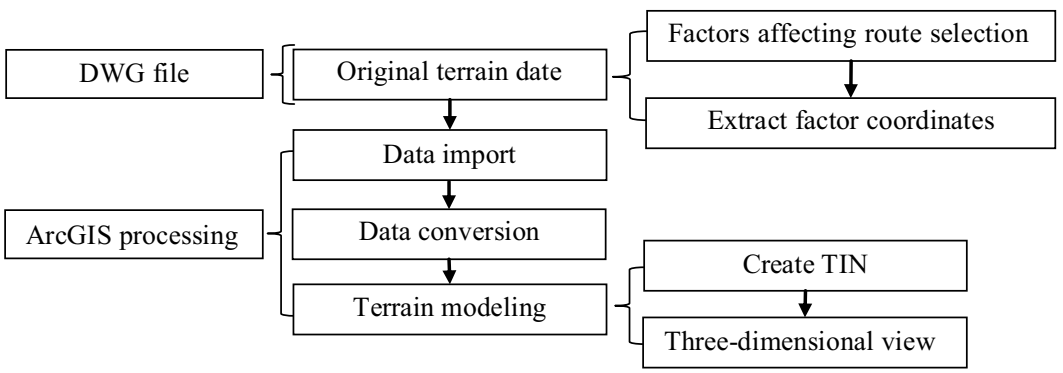

Figure 1. GIS modeling process

\subsection{Construction of Large Strip 3D Model}

When building geographic information model in GIS, it is necessary to clarify all kinds of factors that affect the line direction to make the model information complete. After consulting the relevant information of railway location design and combining with the actual geographical conditions, it is concluded that there are four kinds of factors affecting the line direction, which are surface features, geology, slope and undulation. The original data of CAD cannot be edited in ArcGIS. At this time, it is necessary to convert the data format and extract the coordinates of surface features and unfavorable geology. The specific operation steps are as follows: (1) converted the shape data in ArcMap, generated the triangulation model with the help of "create tin" tool, and trimmed the model of redundant triangulation connection at the turning position. (2) The coordinates of surface features and unfavorable geology on CAD topographic map were imported into ArcMap, and the coordinates were covered with surface features through "3D editor", so as to ensure the accurate position of all bad factors affecting route selection. The three-dimensional model of the large strip terrain is shown in Figure 2.

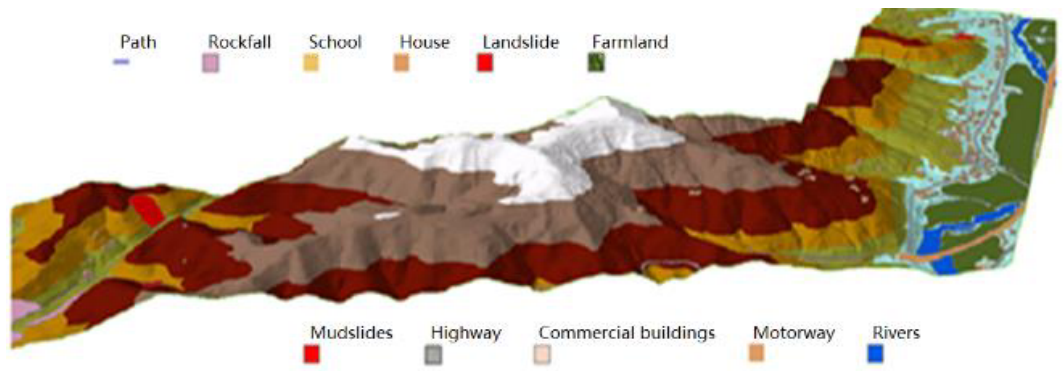

Figure 2. Three-dimensional model of large strip terrain

\section{Cost Path Analysis}

\subsection{Analytic Hierarchy Process Model}

AHP is a systematic method for solving qualitative problems in a quantitative way proposed by Professor Saaty, an American operational research scientist. The core 
problem is to distinguish the primary and secondary relations among the elements, and then solve the weight of the criteria layer. Through the previous study, the elements of the same grade of geology, surface features, slope and undulation were summarized as the criterion layer. Various factors included in ground features and geology, such as road network, house, river, landslide and debris flow, were classified as specific factors.

Using Delphi Method, taking 1-9 as the scale, 5 experts were invited to evaluate the relative importance of each pair of factors affecting route selection, construct judgment matrix and calculate the weight value of each influencing factor, as shown in Table 1. In order to ensure the correctness of weight assignment, it's also necessary to check the consistency of judgment and evidence, that is, to ensure the $C I, R I, C R$ values within the specified range.

Table 1. Classification, assignment and weight of factors affecting route selection

\begin{tabular}{|c|c|c|c|}
\hline $\begin{array}{c}\text { Factors affecting } \\
\text { route selection }\end{array}$ & Classification & Assignment & $\begin{array}{c}\text { Normalized } \\
\text { weight }\end{array}$ \\
\hline \multirow{6}{*}{ Ground object } & commercial building & 9 & \multirow{6}{*}{0.08} \\
\hline & residential housing & 7 & \\
\hline & school & 10 & \\
\hline & road network & 7 & \\
\hline & river & 10 & \\
\hline & farmland & 5 & \\
\hline Slope & & 9 & 0.10 \\
\hline \multirow{3}{*}{ Geological disasters } & mudslide & 19 & \multirow{3}{*}{0.30} \\
\hline & landslide & 19 & \\
\hline & rockfall & 19 & \\
\hline Degree of relief & & 9 & 0.52 \\
\hline
\end{tabular}

The judgment index $C I$ represents the consistency of judgment matrix. If the value of $C I$ is small, it proves that the consistency of judgment matrix is high. The calculation formula of $C I$ is as follows:

$$
C I=\frac{\lambda_{\max }-n}{n-1}
$$

In Eq. (1), $n$ is the sum of diagonal elements in the judgment matrix, and $\lambda_{\max }$ is the maximum eigenvalue of the judgment matrix. In a few cases, $C I=0$ also appears, which shows that the judgment matrix has complete consistency. However, this situation often does not appear in the high-order matrix, so in this situation there is a new judgment index $R I$, which represents the average random consistency. The ratio of $C I$ to $R I$ represents the consistency of judgment matrix. This ratio is recorded as $C R$. The expression of $C R$ is as follows:

$$
C R=\frac{C I}{R I}
$$


In Eq. (2), the value of $C R$ must be less than 0.1, otherwise the judgment matrix needs to be reconstructed. Under the premise of less than 0.1 , the closer the $C R$ value is to 0 , the better the consistency of judgment matrix is.

According to the judgment matrix, three formulas of consistency test were used to test the consistency of judgment matrix, and the results are shown in Table 2.

Table 2. Consistency test

\begin{tabular}{lcccc}
\hline Inspection index & Eigen value $(\boldsymbol{\lambda})$ & CI & RI & CR \\
\hline Calculation results & 4.116613 & 0.038871 & 0.90 & 0.0437 \\
\hline
\end{tabular}

\subsection{Cost Path}

The cost path algorithm is based on the cost distance and path distance algorithm, starting from one or more starting points to reach one or more terminal points. The "shortest path" in GIS refers to the calculation after superposition of "cost". The "shortest path" is the shortest one with the lowest "cost", rather than the "shortest straight line". The specific operation methods are as follows:

The analysis of slope and relief was carried out in ArcMap, and the data grid of slope and relief was reclassified for subsequent calculation. The buffer was set for various influencing factors of line selection, and then the relative line cost was assigned to the buffer. The impact factors of cost were classified and combined into raster layer set according to the criteria. Finally, overlay the "costs" of different raster layers to obtain a comprehensive cost data grid, as shown in Figure 3.

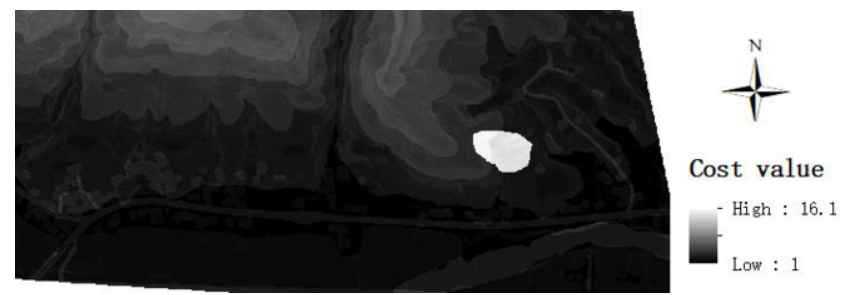

Figure 3. Integrated cost data grid

The establishment of the comprehensive cost model gave the cost value of each grid on the comprehensive cost data set, based on which the lowest cost path was generated. The data analysis of the comprehensive cost model was carried out with the help of cost distance and cost path tool in ArcMap, and the cost path was obtained as shown in Figure 4.
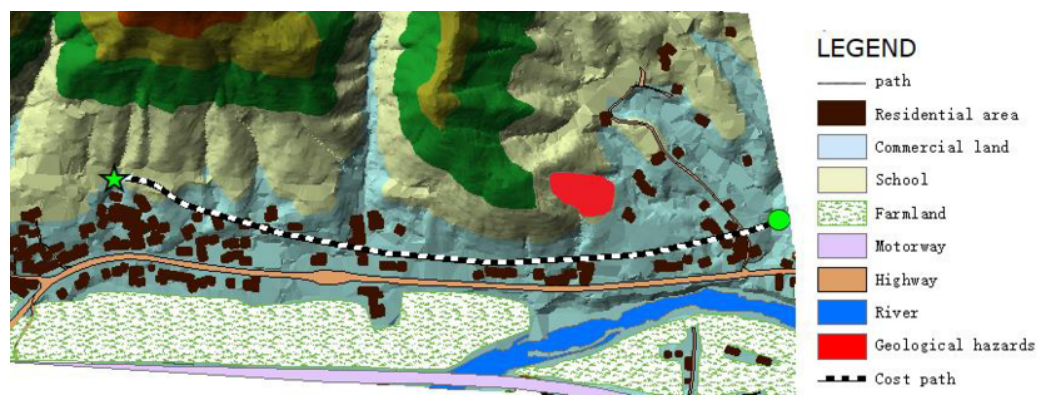

Figure 4. Optimal cost path 
It can be seen from Figure 4 that the selected line passes through relatively flat terrain, far away from steep slopes and ditches, which reduces the difficulty of engineering geology and improves the safety factor of the project; it is far away from the fields and waters, reducing the occupation of crop environment during the construction of the line and reducing the comprehensive cost. Finally, the cost path was further converted into DWG format file, which was convenient to design 3D circuit model with the lowest cost and meet the engineering requirements in BIM software.

\section{BIM Modeling of Line scheme}

The rise of BIM technology has brought unprecedented changes to the field of engineering design. From the abstraction and limitations of traditional $2 \mathrm{D}$ drawings to the stereoscopic intuitivism of $3 \mathrm{D}$ design, it not only enables designers to conduct scheme selection and design more intuitively, but also improves design quality and efficiency.

\subsection{Construction of Line Model Based on Civil 3D}

Civil 3D provides designers with a very comprehensive way of route layout. Through surface editing, road grading and other functions to achieve complex engineering modeling, designers can intuitively see the design effect through $3 \mathrm{D}$ view, thus speeding up the realization process of design concept. The specific design steps of this article are as follows:

- According to the existing cost path route, a limited number of control points were added to the terrain surface using the traverse method, and the curve parameters were preset to automatically fit a route that met the design specifications to complete the planar route design.

- Generated ground line through "create profile view", and then used "profile creation tool" to complete the profile design.

- According to the requirements of the cross-section of the route, components such as rails, slopes, drains, etc. were added to complete the design of the route model assembly, as shown in Figure 5(a).

- After completing the above work in Civil 3D, Create Road tool was used to create a route model on the terrain surface according to the logical relationship, as shown in Figure 5(b).

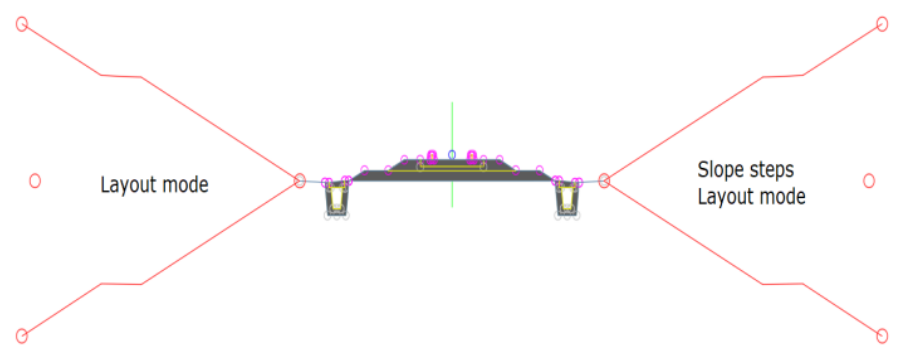

(a). Line assembly 


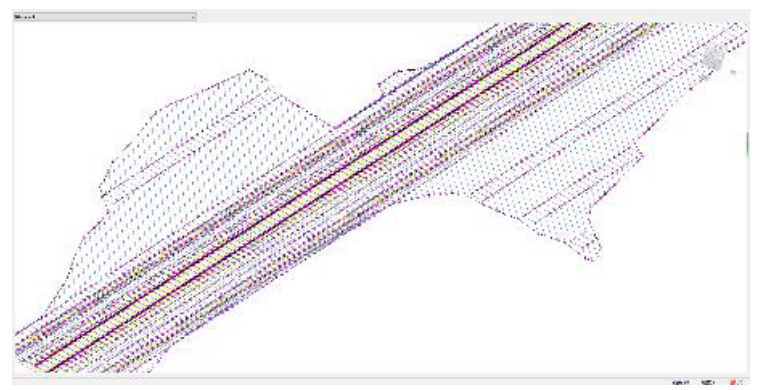

(b). Railway model

Figure 5. Line model

\subsection{Earthwork Calculation}

The earthwork volume of the line can reflect the economic cost of the line construction. In civil $3 \mathrm{D}$, the calculation of excavation and filling volume is to establish two (or more) surfaces in the same area and compare the volume difference between the surfaces. If the surface can completely reflect the actual terrain, then the calculation result of the volume of excavation and filling is also completely accurate.

The basic process of calculating the volume of excavation and filling is: first firstly, created two original terrain surfaces, Secondly, glued the design line surface with the terrain surface, and then used the surface tools in Civil 3D to compare the volume of the two surfaces, and calculated the final volume. A section of railway line is selected from the test area for route selection. The technical and economic indexes of the designed line are compared by using the method above (as shown in Table 3 ).

Table 3. Comparison of technical and economic indexes

\begin{tabular}{|c|c|c|c|c|c|}
\hline & Indexes & Name & Unit & Design route & Actual line \\
\hline 1 & Line length & $\begin{array}{c}\text { Building } \\
\text { length/Operating } \\
\text { length }\end{array}$ & $\mathrm{km}$ & 2.4 & 2.6 \\
\hline 2 & Minimum curve radius & & $\mathrm{m}$ & 1600 & 1200 \\
\hline 3 & earthwork & fill/cut & $10^{3} \mathrm{~m}^{3}$ & $19.523 / 14.602$ & $21.105 / 15.958$ \\
\hline 4 & Net volume & Quantity/ (fill or cut) & $10^{3} \mathrm{~m}^{3}$ & 4.922/fill & $5.189 /$ fill \\
\hline 5 & bridge & Total seats/length & seat $/ \mathrm{m}$ & $2 / 896$ & $2 / 840$ \\
\hline
\end{tabular}

A comparative analysis on the two design schemes above indicates that:

- The net value of total earthwork in the designed line decreased by $5.1 \%$, compared with the real line

- The designed line applies a large minimum radius of curvature, which can improve the running speed of train

- The designed line is $200 \mathrm{~m}$ shorter than the real line based on traditional route selection method.

So far, the construction of Civil 3D line model has been completed. For the followup 3D visualization work, the Civil 3D files were saved in IMX format, which was convenient to open in Infraworks360 software. 


\subsection{Visualization Design of Infraworks360}

The line model was imported into Infraworks360 for visual collaborative design to create a real and observable line model. First, a new model was created in Infraworks360 and the IMX format file was imported. Then, selected the appropriate coordinate system for the model in the configuration options, established the preliminary model, and modified the bridge and tunnel styles in the "manual style" tool for the mountain valley region of the three-dimensional model, as shown in Figure 6.
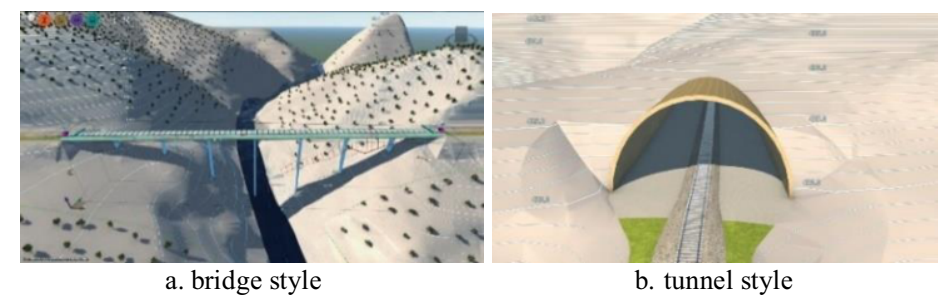

Figure 6. Style palette

In order to improve the visualization effect and make the model more realistic, raster satellite images in Google map were downloaded to build 3D human and natural landscape model to meet the designer's further consideration of the impact of railway engineering construction on environmental problems. Finally, the $3 \mathrm{D}$ circuit model is shown in the figure below.

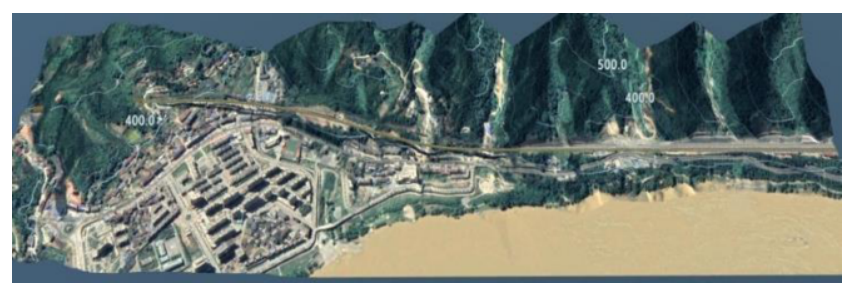

Figure 7. Three-dimensional circuit display model

\section{Conclusion}

In recent years, the integration of BIM and GIS, as a core technology for informationbased construction of large railway projects, has aroused wide concern inside and outside the industry. A section of railway line from Shiquan County to Gaoliang County is selected as the test section. The selection of railway route based on computer aided design and visualization is more objective and efficient than the traditional model. Specifically, the proposed method has the following advantages:

(1) A GIS-based three-dimensional geographical model for a large strip is used to analyze the influencing factors in the selection of railway route. A spatial information analysis model for selection of regional railway route is set up to minimize the comprehensive cost and generate the optimal route automatically. The route is then visualized by BIM in the software like Civil 3D and Infraworks360. The proposed method is practical and effective in solving the problems of traditional route selection 
method, such as limited options, low efficiency, long decision-making cycle and unclear design intent.

(2) When using BIM to calculate the excavated volume of earthwork, the workload in the points of field data acquisition can be greatly reduced, compared with the traditional calculation method of earthwork. A 3D digital terrain model can be built in a more rapid and flexible way to prevent the defects of hand computation (e.g. heavy computational burden, complexity and time-consuming), estimate the cost of earthwork, and control the upfront expense of projects.

\section{Acknowledgement}

The author thanks the tutor and his National Natural Science Foundation of China (51568037) for their help in this article.

\section{References}

[1] Yi SR. Principles of railway location and design. Chengdu: Southwest Jiaotong University Press, 2018.

[2] Garcia-Alvarez A. Design of railway track for speed and high-speed railways. Computing in Science and Engineering. 2014 Dec; 14(4):256-261.

[3] Pan GQ. Research on constraints and countermeasures of railway location. China Railway. 2008 Mar; 3:35-38.

[4] Wang ZM. Methods and ideas of railway route selection in complicated mountainous area. Journal of Railway Engineering Society, 2016 Oct; 33(10):5-9.

[5] Yi SR, Zhu Y, Xu YD. Railway line BIM and digital route selection technology. Beijing: China railway publishing house.2014 Jun.

[6] Tchana Y, Ducellier G, Sébastien Remy. Designing a unique Digital Twin for linear infrastructures lifecycle management. Procedia CIRP. 2019 Apr; 84:545-549.

[7] Kong JL. The Multi-plans Synthetic evaluating in highway routes selection based on GIS. Geomatics and Information Science of Wuhan University. 1999 Sep;24(3): 213-215.

[8] Liu M, Shi HS, Ji CL, Chen XQ. Research on the evaluation of ecological assets loss in railway construction project route selection. E3S Web of Conferences. 2020; 145:2038

[9] Wang MS, Yu JJ. GIS spatial analysis and digitalization of railway line evaluative index. Railway Survey, 2005 Dec; 6:57-60.

[10] Zhang XD. A study on applicable analysis model for railway location design in the environment of GIS. Railway Survey, 2005 Aug; 4:9-12.

[11] Gao YX, Han F, Duan XF. Study on decision-making method for route alignment based on spatial similarity theory. Railway Standard Design. 2018 May;2:44-48.

[12] Fan DK, Han ZJ, Li HL. Research on the standards and technology of BIM and GIS fusion for railway information construction. Railway Technical Innovation, 2015 Jun; 3:35-40.

[13] Cao F. Discussion on comprehensive application of BIM+GIS in railway industry. China New Telecommunications, 2015 Mar; 7:37-40.

[14] Wan Nor Fa'aizah Wan Abdul Basir, Zulkepli Majid, Uznir Ujang, Albert Chong. 2018. Integration of GIS and BIM techniques in construction project management - A review. International Archives of Photogrammetry and Remote Sensing. Spatial Inf. Sci. XLII-4/W9, 307-316.

[15] Wang H, Pan Y, Luo X, 2019. Integration of BIM and GIS in sustainable built environment: A review and bibliometric analysis. Automation in Construction, 103, pp.41-52.

[16] Wang W. Construction and application of the railway BIM spatial information system based on 3D GIS. Bulletin of Surveying and Mapping. $2020 \mathrm{Jul}$; 7:138-142.

[17] Wang Y. The design and research of the railway operation and maintenance management information platform based on BIM technology. Railway Technical Innovation. 2020 Jun; 3:40-44. 